\title{
COST Action 625 Results: Monitoring of the Kaparelli fault, 2003-2006
}

\author{
Ganas A. ${ }^{1}$, Drakatos G. ${ }^{1}$, Bosy J. ${ }^{2}$, Petro L. ${ }^{3}$, Kontny B. ${ }^{2}$, Stercz M. ${ }^{3}$, Melis N. \\ S. ${ }^{1}$, Cacon S. ${ }^{2}$, Papanikolaou M. ${ }^{1}$, Pirentis A. ${ }^{1}$, and Kiratzi A. \\ ${ }^{1}$ Institute of Geodynamics, National Observatory of Athens, 11810 Athens, Greece \\ aganas@gein.noa.gr \\ ${ }^{2}$ Institute of Geodesy and Geoinformatics, Agricultural University of Wroclaw, Grunwaldzka 53, \\ 50-357 Wroclaw, Poland \\ ${ }^{3}$ Geological Survey of Slovak Republic, Jesenskeho 8, SK-040 01 Kosice, Slovak \\ Republic \\ ${ }^{4}$ Department of Geophysics, Aristotle University of Thessaloniki, 54124 Thessaloniki, Greece
}

\begin{abstract}
Since November 2003 a collaborative group between Greek, Polish, and Slovak colleagues installed a dense network of non-permanent GPS stations and extensometers to monitor active faults in the eastern end of the Gulf of Corinth, central Greece. The network includes eleven GPS stations across the Kaparelli fault and the Asopos rift valley to the east and two TM-71 extensometers that were installed on the Kaparelli fault plane. The motions recorded by the TM-71 instruments show agreement with long-term fault kinematics. The GPS network has been measured in three campaigns $(2004,2005$ \& 2006) with very good accuracies (1-4 $\mathrm{mm}$ in the horizontal plane). Given that the total offset on the Kaparelli fault is small, and the geological data suggesting a segmented character of this fault, we expect in the near future to differentiate fault slip and strain accumulation among segments.
\end{abstract}

Key words: Active faults, GPS, TM-71, Kaparelli, Corinth Gulf, earthquakes, strain.

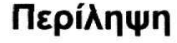

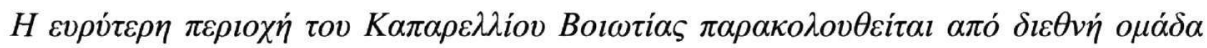

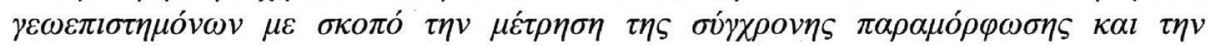

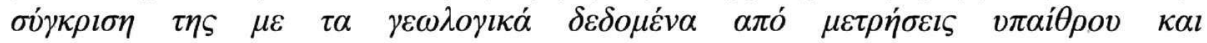

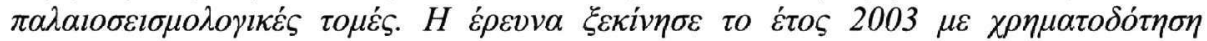

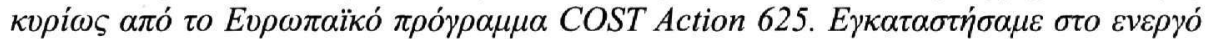

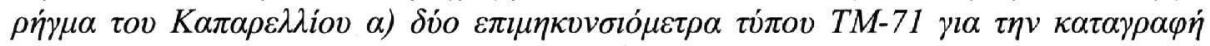

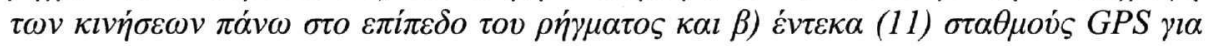

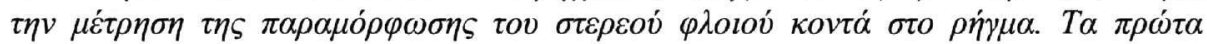

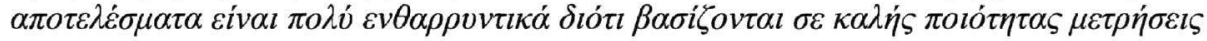

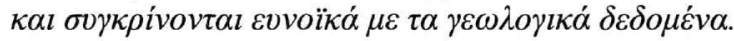

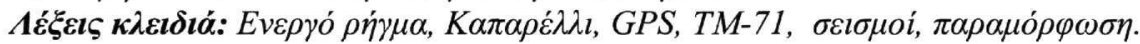




\section{Introduction}

Central Greece is one of the most tectonically active and rapidly extending regions in the world. Surface topography and geomorphology are clearly associated with seismic activity along large normal faults (Armijo et al. 1996). Extension is mainly directed N-S (Clarke et al. 1998) with greater rates towards the west. In February - March 1981 a sequence of three earthquakes with magnitudes greater than 6.3 struck the eastern Gulf of Corinth (King et al. 1985, Hubert et al. 1996). North-dipping surface breaks were noted the morning after the first two events on the southern side of the Gulf (Perachora Peninsula) and south-dipping ruptures appeared on the northern side of the Gulf (Kaparelli region) as a result of the third event (Fig. 1; data from Jackson et al. 1982). In both areas seismic motion occurred along basin-bounding faults bringing in contact Mesozoic limestone and alluvial deposits as well as colluvium. Focal mechanisms of small and shallow earthquakes (data from Ambraseys and Jackson 1990) also show normal faulting with the active fault plane dipping at about $45^{\circ}$ for faults at the eastern end of the Gulf of Corinth including Kaparelli. Our group used two (2) TM-71 extensometers to measure fault-motion on a monthly basis and GPS satellite technology to pinpoint the location of survey stations down to a fraction of a centimetre. We set up a pillar-mounted antenna over a survey station and attached a data receiver to the antenna. The antenna picks up GPS satellite signals and stores the information in the data receiver. After two days of observations, the set-up is taken down and we downloaded the data onto computers for processing. After processing, the data is used to determine the station locations and the strain across active faults.

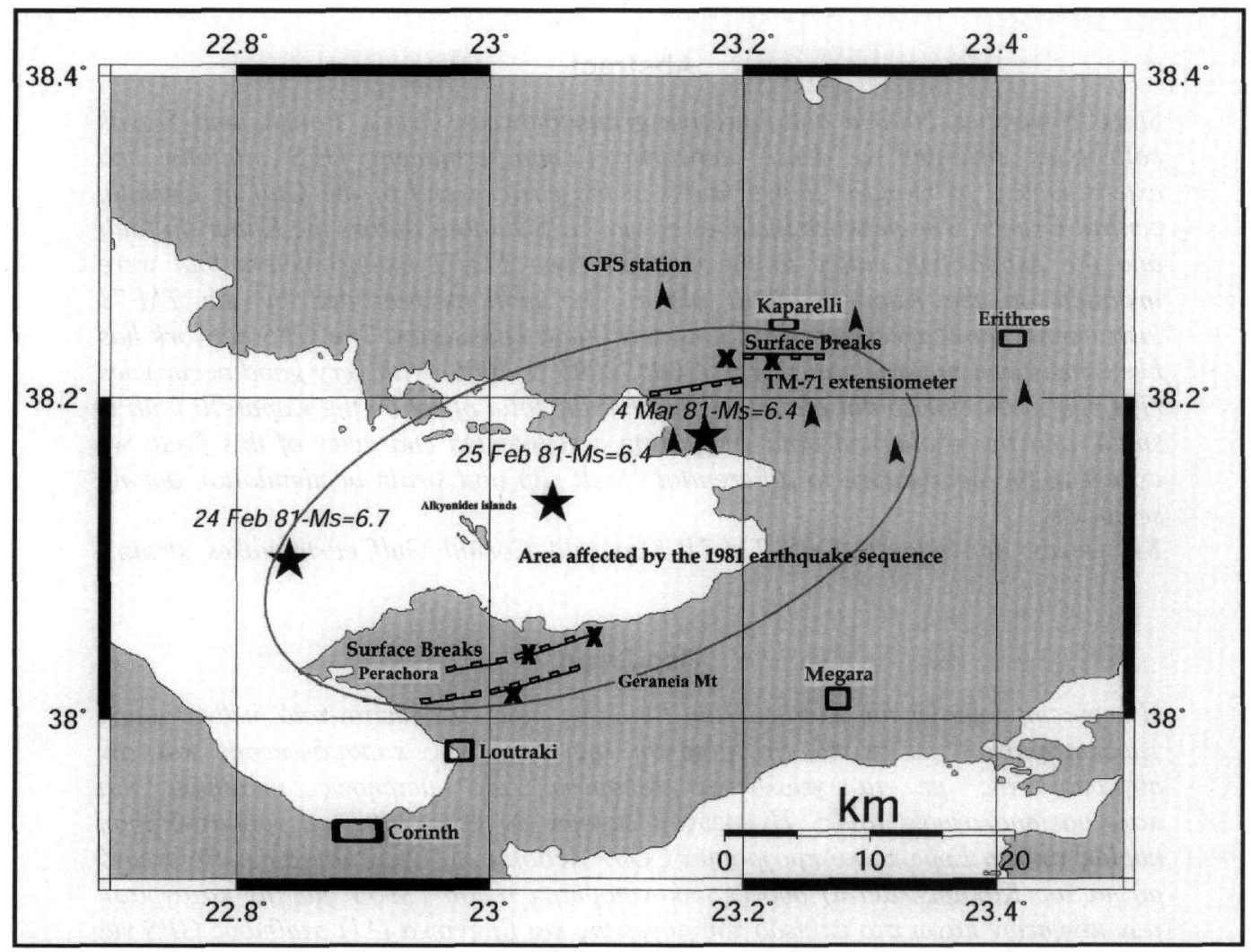

Figure 1 - Map of the study area showing epicentres of the 1981 earthquake sequence (stars). $X$ signs point to TM-71 instrument locations and black arrows indicate locations of nonpermanent GPS stations installed during 2003. Lines with barbs indicate normal faults that ruptured during the 1981 earthquake sequence 


\section{Monitoring the activity of the Kaparelli Fault}

The Kaparelli Fault consists of three segments, two of which were ruptured in 1981 (Jackson et al. 1982). The two-ruptured segments form left-stepping en echelon geometry, while the third northwestern segment of the fault did not rupture (Fig. 2). The fault segments are clearly expressed at the surface by nearly continuous scarps. The footwall elevation is $600 \mathrm{~m}$ and lithology is composed of hard, Mesozoic limestone. The hanging wall block forms a small basin and contains approximately $200 \mathrm{~m}$ of fluvial-terrestrial deposits of Pleistocene age as well as Holocene alluvium. Recently, three trenches have been excavated across the Kaparelli Fault (Pavlides et al. 2003, Kokkalas et al. in press). Their stratigraphic record shows at least three events during the Holocene period, with the 1981 event included. The estimated mean slip rate is $0.28 \mathrm{~mm} / \mathrm{yr}$. Colluvial tectonostratigraphy and analysis of displacements on key horizons suggests surface rupturing events in the order of $0.7-1 \mathrm{~m}$.

In order to measure the kinematics of deformation in 3-D our group has installed a) a dense GPS network and b) two (2) extensometers. The details of installation of instruments and project rationale are given in Drakatos et al. (2005) and Cacon et al. (2005). In summary, our group has begun monitoring of the Kaparelli fault area since May 2003. On May 26, 2003 we installed an extensometer of TM-71 type (Kostak and Cruden 1990). At this site the fault strikes $\mathrm{N} 77^{\circ} \mathrm{E}$ and dips $77^{\circ}$ towards the South. A second instrument was installed on July 15, 2004. The TM-71 readings are recorded on a nearly monthly basis by NOA. In addition, a dense GPS network has been installed comprising six (6) stations. The network was deployed on November, 11-12 2003 and its first measurement took place in May 2004. The network was expanded on March 31, 2005. Five (5) new stations were installed inside the Asopos rift valley (see Figure 4 below). Both subnetworks were measured during May 2005 and May 2006.

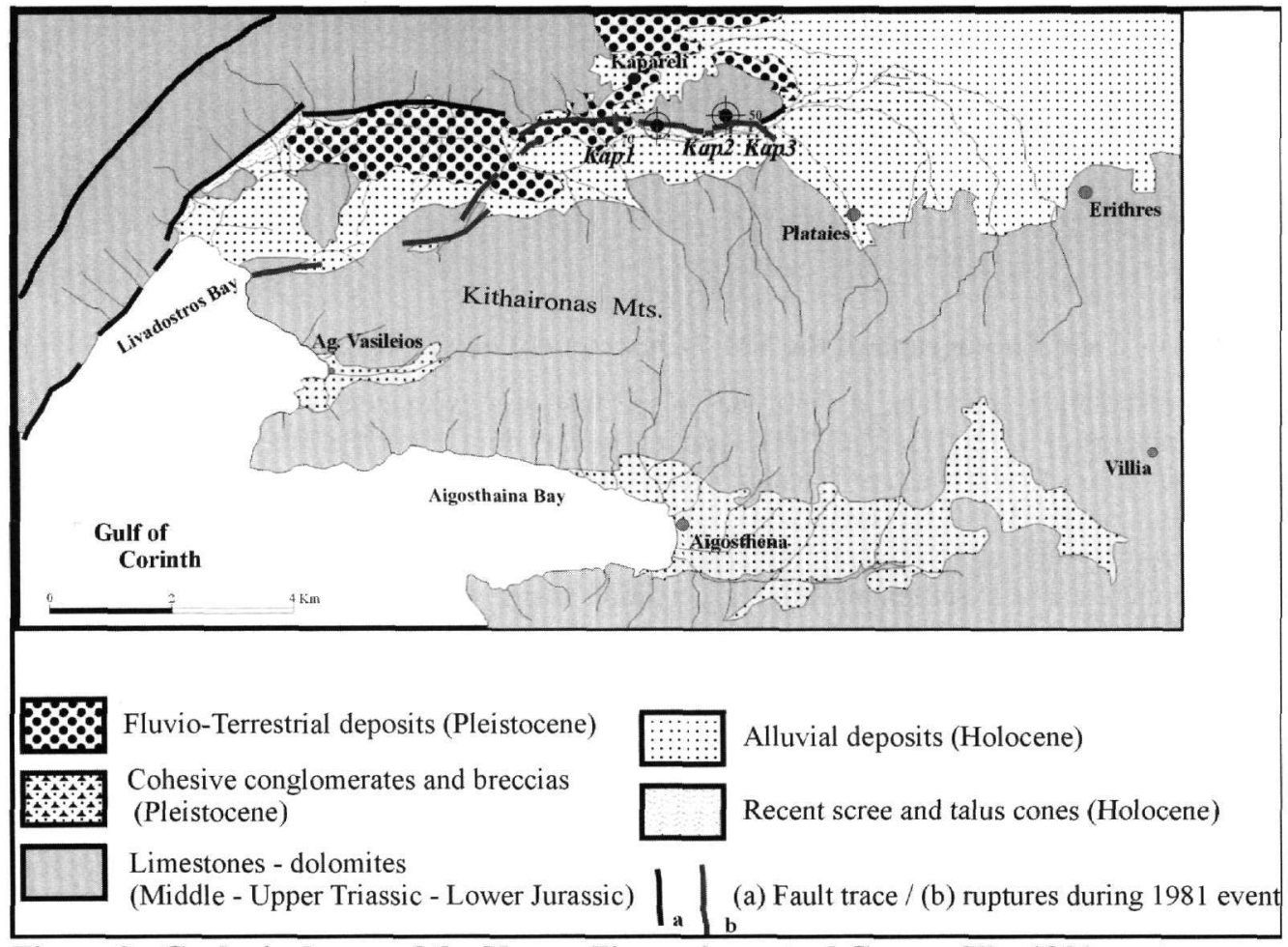

Figure 2 - Geological map of the Kaparelli area in central Greece. The 1981 ruptures are shown in red. Trench positions are denoted by Kap1, Kap2 and Kap3. Circle symbols point to TM-71 installations. Map after Pavlides et al. 2003 


\section{Monitoring fault motion using TM-71 Instruments}

The TM-71 is designed to monitor long-term displacements in all three directions in space at millimetre scale. It is capable of recording displacements by producing interference patterns on optical grids (Kostak 1991) in the form of black and white fringes. It mainly consists of two identical indicators consisting of two superimposed glass plates. On each glass plate a grid of equidistant circles and a grid consisting of equidistant parallel lines have been etched. The interference patterns produced by the circular grids consist of a number of symmetrically arranged fringes stretching radially from the centre. The number $\mathrm{N}$ of the fringes on one side of the diameter (symmetry axis) provides the length of the displacement vector while the orientation of the symmetry axis provides its direction (Fig. 3). The advantage of this instrument is that, it involves no electromechanical parts and it can be easily installed across active faults by use of steel bars (e.g. Maniatis et al. 2003, Drakatos et al. 2005).

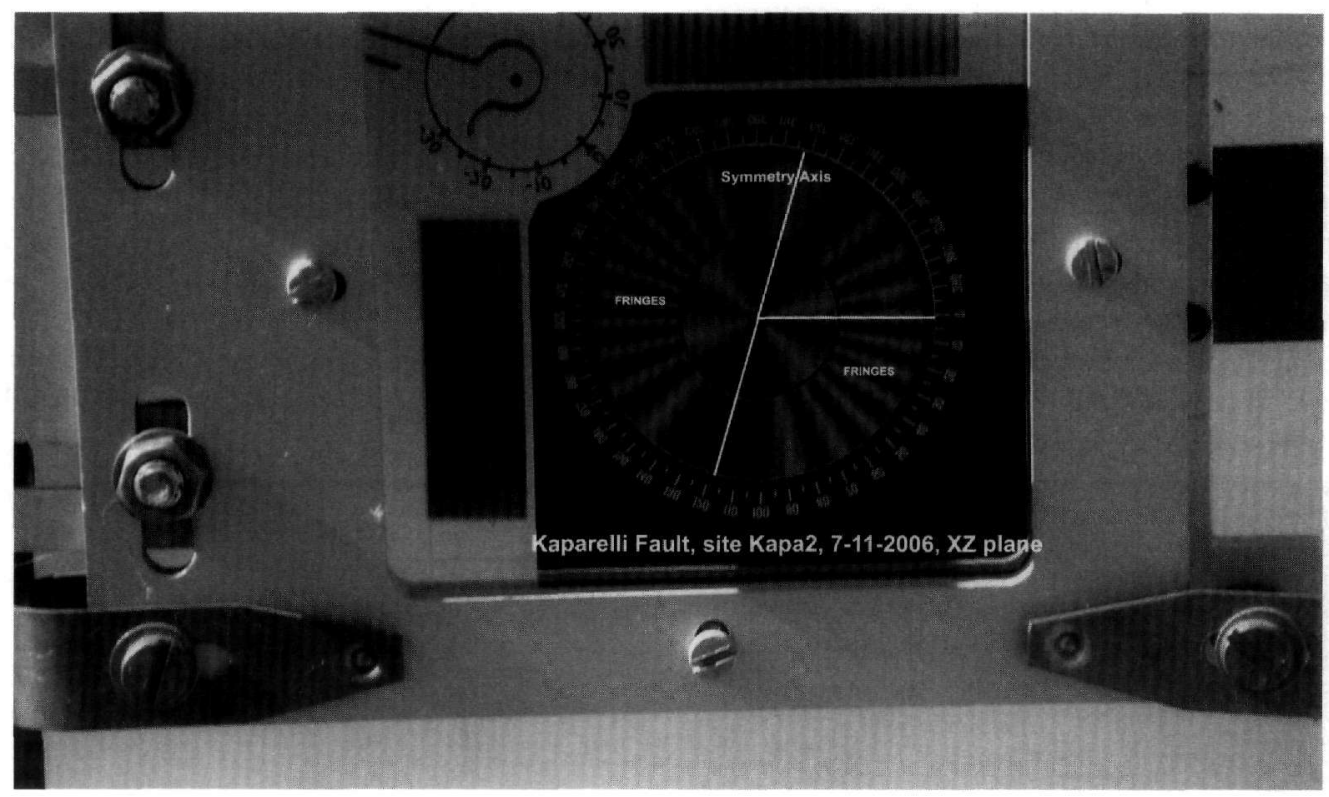

Figure 3 - Field Photograph of the TM-71 instrument on site Kapa2 (7 November 2006)

The 2003 installation was done at the trench Kap2 that was excavated across the Kaparelli fault (Fig. 2; Drakatos et al. 2005). The 2004 installation was done against a free surface of the fault plane, about $2 \mathrm{~km}$ to the west of locality Kap2, near the asphalt road from Kaparelli to Agios Vasilios. Our observations for site Kapa1 span a period of 3 years so it is possible to make a preliminary interpretation (Fig. 4). Initial change in X-axis (up to the end of 2003) is probably the result of concrete block settlement after its creation inside the trench. Since 2004 we observe opening of the order of $0.2-0.4 \mathrm{~mm}$ that is in agreement with average fault slip rate from past earthquakes. We also observe a seasonal effect of opening-closure that is probably related to the temperature variation of the steel bar which is directly exposed to sunlight. Displacement along Zaxis is relatively stable. Along the axis Y (horizontal; along the fault strike) observed motion is dextral oblique slip. A similar pattern is observed in the rotation plot (Fig. 4) for the plane XY (the horizontal plane) which is stable since early 2004. Rotation sense is negative because the nearfault side is compressed due to shear. This dextral shear motion is consistent with the slip vector model of Roberts and Ganas (2000) that predict oblique slip vectors at normal fault tips. In Kapa2 the observation period is shorter (about 2 years) but the fault-normal opening is stable (X-axis; Fig. 4). The signal along the two other axes is less clear. However, the rotation plot shows positive values that indicate sinistral motion on the horizontal plane (XY). 


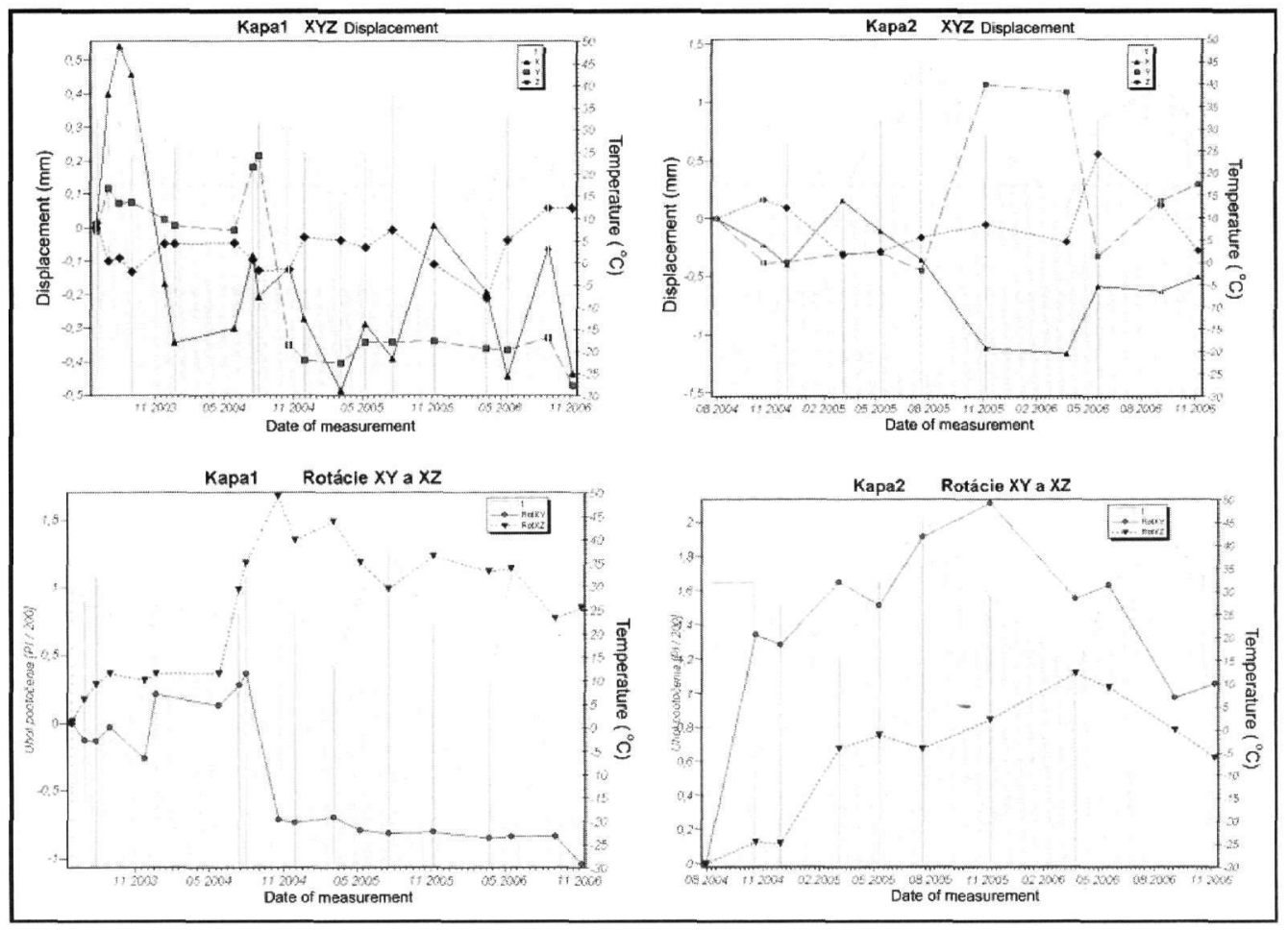

Figure 4 - (Left) Displacement - Time diagram for site Kapa1 along the Kaparelli Fault. (Right) Displacement - Time diagram for site Kapa2. Accuracy of measurements better than $0.1 \mathrm{~mm}$ (Stemberk et al. 2003). Bottom graphs show rotation of XY (horizontal) and XZ (vertical) planes of the instrument, respectively. Units are in grades ( 1 circle $=400$ grades). The position of the $X, Y$, and $Z$ axes of the instrument corresponds respectively to: $(X)$ the direction perpendicular to the fault or fault-normal motion, (Y) direction parallel to fault strike or the strike slip motion along the fault surface and $(Z)$ vertical direction or the dip slip component of motion

\section{Monitoring regional deformation using GPS Instruments}

The motion of crustal blocks in central Greece can be described in a first approximation by a combination of translation and rotation (Goldsworthy et al. 2002). Strain accumulation occurs across major rift zones including the Gulf of Corinth and Gulf of Evia (Clarke et al. 1998). Strain is not localized uniformly but with noticeable variations both in azimuth and amplitude. This difference could be explained by either along-strike changes in fault behavior or in material properties. Geological data by Roberts and Ganas (2000) indicate the long-term strain patterns along normal faults are not uniform and that a systematic difference exists between the average extension directions in central Greece (Gulf of Corinth vs Gulf of Evia). KAPNET (Fig. 5) was designed with two things in mind: a) to map strain build-up along the Kaparelli fault - Asopos rift valley for better estimating earthquake potential and b) to compare geodetic strain patterns with geological strain patterns. A third objective is to measure local variations in strain rate that might reveal the mechanical properties of earthquake faults.

The KAPNET network spans about 1-5 kilometers on either side of the surface trace of the Kaparelli fault (Fig. 5). Baseline length rates of change from this network can be used to measure the near-fault strain rate. The network was measured for the first time in May 2004 using the ASTHECH receivers of the Polish group. In particular stations ERIT, KAPA and TAPS (Fig. 4) 
were surveyed using ASHTECH Zxtreme instruments and ASH701975.01A antennas where remaining stations were surveyed using Z-XII instruments and ASH700718B antennas. Station AGTR (Fig. 5) was used as the base station. The initial network was expanded during 2005 with the installation of five (5) more stations. All NOA stations were measured using Leica 1200 receivers.

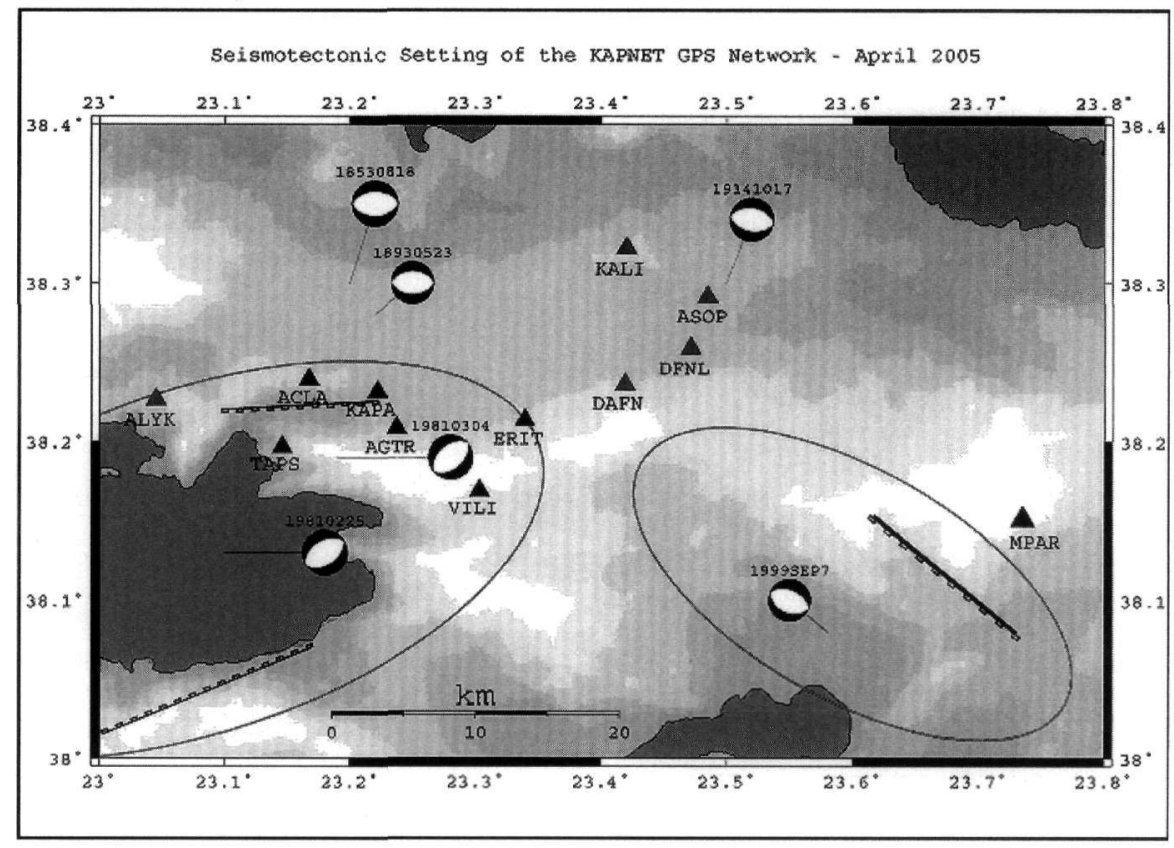

Figure 5 - Elevation map of the study area showing the locations of the GPS stations. Dark red triangles show the $\mathbf{2 0 0 3}$ installations. Beachballs represent fault plane solutions of strong, shallow earthquakes

The GPS observations from 2005 and 2006 campaigns were processed with the Bernese GPS postprocessing software (version 4.2; Hugentobler et al. 2001). The data were combined with regional permanent sites MATE (Italy) and IGD1 (2005), NOA1 (2006; Athens, Greece). The solutions were then transformed into ITRF2000 (Altamini et al. 2002; each daily session separately). A special data processing strategy was developed for the local precise network with the following issues and assumptions (Bosy and Kontny 1998, Bosy et al. 2003): a) Global ionosphere model CODE for a phase ambiguity resolution b) Antenna phase centres calibrated according to the NGS, c) Troposphere model - the Niell mapping function without a priori model; residual atmosphere zenith delays were estimated for one-hour intervals and d) Precise ephemeris computed by the Centre of Orbit Determination in Europe (CODE) to determine satellite positional data.

All KAPNET positions were resolved with Root-Mean-Square residuals less than $2 \mathrm{~mm}$ (on average; Fig. 6). The antenna parameters of the 2005 and 2006 campaigns are given in Table 1. Our first results include coordinates and RMS errors of KAPARELLI local network points for two years 2005 and 2006 . They were generated by connecting the daily solutions using the ADDNEQ program (Brockmann 1996, Hugentobler et al. 2001). Computed ITRF2000 (observation epoch) $\varphi$ and $\lambda$ coordinates, ellipsoidal heights and their RMS errors are collected in Table 2 . The accuracy of determined coordinates $(\varphi, \lambda$ and $h$ ) representing un-weighted RMS values of coordinate residuals taken from each year (comparison of station coordinates from each session with respect to the combined solution in $\mathrm{mm}$ ) is shown in Figure 6. The un-weighted RMS values computed from repeated observations give more realistic accuracy of stations coordinates. They provide conditions for detecting horizontal movements of the stations at the $<5 \mathrm{~mm}$ level (maximum) and at $<2 \mathrm{~mm}$ level (mean value). 

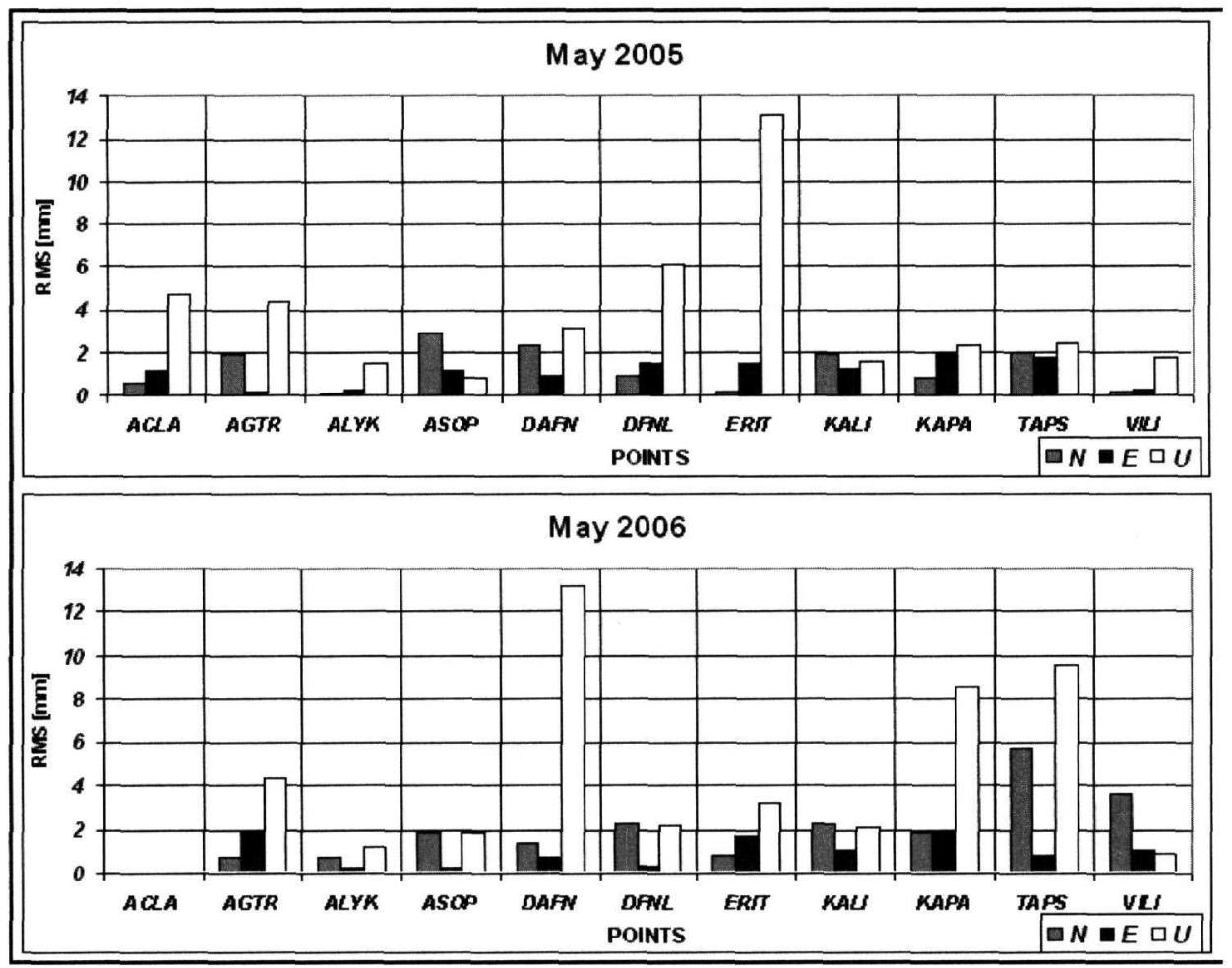

Figure 6 - The un-weighted RMS values with respect to the combined solution in mm

\section{Discussion - Conclusions}

a) Data from the TM71 instruments along the Kaparelli Fault show fault-normal opening as expected for this normal fault. A seasonal effect is also discernible in the data of Kapal instrument (Fig. 4). Also, the shear motion in Kapal is dextral in agreement with nonuniform strain patterns along active normal faults (Roberts and Ganas 2000).

b) Three (3) similar instruments have been installed in the Perachora peninsula by Maniatis et al. (2003; Fig. 1). Given that Holocene fault slip rates at these localities differ by a factor of five (5) or even more it is important to compare 3-D strain measurements in order to estimate inter-seismic strain accumulation along the two fault zones. Another issue concerns the identification of instrument-induced errors on our measurements and their estimation. The advantage that TM-71 has no electronics parts is counterbalanced by the infinitesimal deformations caused by climatic fluctuations (precipitation, temperature). For example a seasonal effect along the $\mathrm{X}$-axis is visible in the 16-year data series from the Simitli graben in SW Bulgaria (Dobrev and Kostak 2000).

c) The data processing of repeated satellite GPS standards provide conditions for detecting horizontal movements at our stations at $2 \mathrm{~mm}$ level (on average). Taking into account the mean fault movement rate of about $0.3 \mathrm{~mm} / \mathrm{y}$, indicated by paleoseismology, significant displacement across Kaparelli can be detected by GPS after 4-7 years of observations. With data of such precision we could address two important questions: (1) is there systematic variation along strike in the near-fault strain rate? Variations along strike could be explained by spatial changes in the depth to which the fault is locked in the inter-seismic period, or by variations in the elastic properties of rocks near the fault zone. (2) How well can a single elastic model fit both the near-field and far-field strain observed geodetically? 
Table 1 - Parameters of the GPS antennas of the Kaparelli (Greece) research area during the 2005 and 2006 field observation campaigns. Height is in metres

\begin{tabular}{|c|c|c|c|c|c|c|c|}
\hline \multicolumn{8}{|c|}{2005} \\
\hline \multicolumn{4}{|c|}{130} & \multicolumn{4}{|c|}{131} \\
\hline POINT & ANT. TYPE & h-OBS & h-RED & POINT & ANT. TYPE & h-OBS & h-RED \\
\hline$\overline{\mathrm{ACLA}}$ & ASH700718B & 0.8290 & 0.7654 & ACLA & ASH700718B & 0.8300 & 0.7664 \\
\hline AGTR & ASH700936D M & 0.7640 & 0.7262 & AGTR & ASH700936D M & 0.7640 & 0.7262 \\
\hline ERIT & ASH701975.01Agp & 0.7810 & 0.7380 & ERIT & ASH701975.01Agp & 0.7830 & 0.7400 \\
\hline KAPA & ASH701975.01Agp & 0.8080 & 0.7650 & KAPA & ASH701975.01Agp & 0.8070 & 0.7640 \\
\hline TAPS & ASH701975.01Agp & 0.8140 & 0.7710 & TAPS & ASH701975.01Agp & 0.8140 & 0.7710 \\
\hline VILI & ASH700718B & 0.8150 & 0.7514 & VILI & ASH700718B & 0.8150 & 0.7514 \\
\hline ALYK & LEIAT502 & 0.7230 & 0.6672 & ALYK & LEIAT502 & 0.7230 & 0.6672 \\
\hline ASOP & LEIAX1202 & 0.7500 & 0.6880 & ASOP & LEIAX1202 & 0.7500 & 0.6880 \\
\hline DAFN & LEIAX1202 & 0.7210 & 0.6590 & DAFN & LEIAX1202 & 0.7210 & 0.6590 \\
\hline DFNL & LEIAX1202 & 0.7390 & 0.6770 & DFNL & LEIAX1202 & 0.7390 & 0.6770 \\
\hline KALI & LEIAX1202 & 0.7230 & 0.6610 & KALI & LEIAX1202 & 0.7230 & 0.6610 \\
\hline \multicolumn{8}{|c|}{2006} \\
\hline \multicolumn{4}{|c|}{122} & \multicolumn{4}{|c|}{123} \\
\hline POINT & ANT. TYPE & h-OBS & h-RED & POINT & ANT. TYPE & h-OBS & h-RED \\
\hline$\overline{A C L A}$ & ASH700718B & 0.8350 & 0.7714 & $\overline{A C L A}$ & ASH700718B & 0.8350 & 0.7714 \\
\hline AGTR & ASH700936D_M & 0.7640 & 0.7292 & AGTR & ASH700936D M & 0.7640 & 0.7292 \\
\hline ERIT & ASH701975.01Agp & 0.7810 & 0.7380 & ERIT & ASH701975.01Agp & 0.7810 & 0.7380 \\
\hline KAPA & ASH701975.01Agp & 0.8070 & 0.7640 & KAPA & ASH701975.01Agp & 0.8070 & 0.7640 \\
\hline TAPS & ASH701975.01Agp & 0.8120 & 0.7690 & TAPS & ASH701975.01Agp & 0.8120 & 0.7690 \\
\hline VILI & ASH700718B & 0.8200 & 0.7564 & VILI & ASH700718B & 0.8210 & 0.7574 \\
\hline ALYK & LEIAT502 & 0.6910 & 0.6910 & ALYK & LEIAT502 & 0.6910 & 0.6910 \\
\hline ASOP & LEIAX1202 & 0.6910 & 0.6910 & ASOP & LEIAX1202 & 0.6910 & 0.6910 \\
\hline DAFN & LEIAX1202 & 0.6910 & 0.6910 & DAFN & LEIAX1202 & 0.6910 & 0.6910 \\
\hline DFNL & LEIAX1202 & 0.6910 & 0.6910 & DFNL & LEIAX1202 & 0.6910 & 0.6910 \\
\hline KALI & LEIAT502 & 0.6910 & 0.6910 & KALI & LEIAT502 & 0.6910 & 0.6910 \\
\hline
\end{tabular}

Table 2 - The ITRF 2000 coordinates of the KAPNET stations

\begin{tabular}{|c|c|c|c|c|c|c|c|c|c|c|}
\hline \multirow{2}{*}{ Point } & \multicolumn{3}{|c|}{$\varphi$} & \multicolumn{3}{|c|}{$\lambda$} & h & $\operatorname{RMS} \varphi$ & RMS A & RMS h \\
\hline & \multicolumn{3}{|c|}{ [o' "] } & & \multicolumn{2}{|c|}{$\left[0^{\prime \prime}\right]$} & [m] & {$[\mathrm{mm}]$} & {$[\mathrm{mm}]$} & {$[\mathrm{mm}]$} \\
\hline \multicolumn{11}{|c|}{ ITRF2000 EPOCH: 2005-05-10 23:59:45 } \\
\hline ACLA & 38 & 14 & 20.457830 & 23 & 10 & 1.655841 & 473.2161 & 0.5 & 0.7 & 3.7 \\
\hline AGTR & 38 & 12 & 29.119021 & 23 & 14 & 13.982700 & 578.4204 & 0.5 & 0.7 & 3.7 \\
\hline ALYK & 38 & 13 & 34.536100 & 23 & 2 & 42.984761 & 474.9853 & 0.7 & 0.7 & 4.9 \\
\hline ASOP & 38 & 17 & 28.851765 & 23 & 29 & 6.323049 & 321.9817 & 0.5 & 0.7 & 3.7 \\
\hline DAFN & 38 & 14 & 8.585989 & 23 & 25 & 7.455789 & 533.3963 & 0.5 & 0.7 & 3.7 \\
\hline DFNL & 38 & 15 & 31.194095 & 23 & 28 & 16.535688 & 357.5885 & 0.5 & 0.7 & 3.7 \\
\hline ERIT & 38 & 12 & 47.859336 & 23 & 20 & 21.377514 & 474.0419 & 0.5 & 0.7 & 3.9 \\
\hline KALI & 38 & 19 & 18.825944 & 23 & 25 & 14.223037 & 395.7988 & 0.5 & 0.7 & 3.9 \\
\hline KAPA & 38 & 13 & 52.699457 & 23 & 13 & 18.760112 & 340.7526 & 0.5 & 0.7 & 3.7 \\
\hline TAPS & 38 & 11 & 47.745238 & 23 & 8 & 45.103563 & 481.9591 & 0.5 & 0.7 & 3.9 \\
\hline VILI & 38 & 10 & 7.788711 & 23 & 18 & 11.234132 & 694.3970 & 0.5 & 0.7 & 3.7 \\
\hline \multicolumn{11}{|c|}{ ITRF2000 EPOCH: 2006-05-02 23:59:45 } \\
\hline ACLA & 38 & 14 & 20.457462 & 23 & 10 & 1.656128 & 473.2449 & 0.5 & 0.5 & 3.1 \\
\hline AGTR & 38 & 12 & 29.118592 & 23 & 14 & 13.982988 & 578.4606 & 0.3 & 0.3 & 2.0 \\
\hline ALYK & 38 & 13 & 34.535574 & 23 & 2 & 42.985050 & 475.0196 & 0.4 & 0.5 & 3.0 \\
\hline ASOP & 38 & 17 & 28.851322 & 23 & 29 & 6.323437 & 322.0029 & 0.3 & 0.4 & 2.3 \\
\hline DAFN & 38 & 14 & 8.585571 & 23 & 25 & 7.456152 & 533.3879 & 0.4 & 0.5 & 2.7 \\
\hline DFNL & 38 & 15 & 31.193592 & 23 & 28 & 16.535760 & 357.6028 & 0.3 & 0.4 & 2.1 \\
\hline ERIT & 38 & 12 & 47.858913 & 23 & 20 & 21.377813 & 474.0702 & 0.3 & 0.4 & 2.1 \\
\hline KALI & 38 & 19 & 18.825917 & 23 & 25 & 14.223237 & 395.8117 & 0.3 & 0.4 & 2.7 \\
\hline KAPA & 38 & 13 & 52.699048 & 23 & 13 & 18.760358 & 340.7809 & 0.4 & 0.4 & 2.4 \\
\hline TAPS & 38 & 11 & 47.744646 & 23 & 8 & 45.103803 & 481.9939 & 0.3 & 0.4 & 2.1 \\
\hline VILI & 38 & 10 & 7.788286 & 23 & 18 & 11.234429 & 694.4191 & 0.3 & 0.3 & 2.0 \\
\hline
\end{tabular}


d) The large E-W faults of the Gulf of Corinth slip fast (1-2 mm/yr) and terminate towards the south of the Kaparelli Fault, while the large normal faults of the Parnitha region to the east slip at about five (5) to ten (10) times less $(0.2-0.4 \mathrm{~mm} / \mathrm{yr}$; Ganas et al. 2004). It is interesting to map this transition in fault slip rates by using the GPS measurements of KAPNET. Our first results (Fig. 6) point to an excellent quality of GPS data that will provide stable solutions. A second point concerns the total offset on the Kaparelli fault that is small $(<200 \mathrm{~m})$, while the geological data suggest that it is segmented. So our GPS measurements will differentiate strain accumulation among the segments. These observations will also shed light into fault growth processes as Kaparelli is an early phase in the development of large normal faults that involves the merging of two or more faults of differing strikes, rather than the steady lengthening of a single fault segment.

e) The results from the GPS observations will help us establish both the magnitude and direction of geodetic strain and compare it with the Holocene faulting record as published in Pavlides et al. (2003) and Kokkalas et al. (in press). The orientation of the strain axes will be also compared with the configuration of the rupture zones of both the 1981 and the 1999 earthquakes (Fig. 5).

\section{Acknowledgments}

This research was funded by COST Action 625, the General Secretariat for Research (Greece) and the National Observatory of Athens. We are indebted to our COST colleagues for many stimulating discussions. The NOA GPS poles were constructed at the NESTOR workshop in Pylos. We acknowledge helpful discussions by B. Kostak, George Stavrakakis, Spiros Pavlides, Yannis Koukouvelas, Andrei Gosar, Luigi Piccardi, Emanuele Tondi and Vincenzo Spina. Many thanks are due to Mr. Errikos Skassis for this help with GPS instrumentation. We also thank two anonymous reviewers for comments.

\section{References}

Altamini, Z., Sillard, P., and Boucher, C., 2002. ITRF2000: A new release of the International Terrestrial Reference Frame for Earth Science applications, J. Geoph. Res., 107 (B10), 2214, doi: 10.1029/2001JB000561.

Ambraseys, N.N., and Jackson, J.A., 1990. Seismicity and associated strain of central Greece between 1890 and 1988, Geophysical J. Int., 101, 663-708.

Armijo, R., Meyer, B., King, G.C.P., Rigo, A., and Papanastasiou, D., 1996. Quaternary evolution of the Corinth Rift and its implications for the Late Cenozoic evolution of the Aegean, Geophys. J. Int., 126, 11-53.

Bosy, J., and Kontny, B., 1998. Strategy of GPS data processing in local geodynamical networks, Reports on Geodesy No. 9(39), Warsaw University of Technology, Institute of Geodesy and Geodetic Astronomy, 105-113pp.

Bosy, J., Figurski, M., and Wielgosz, P., 2003. A strategy for GPS data processing in a precise local network during high solar activity, GPS Solutions, Volume 7, Number 2 SpringerVerlag, 120-129pp.

Brockmann, E., 1996. Combination of Solutions for Geodetic and Geodynamic Applications of the Global Positioning System (GPS) PhD. dissertation, Astronomical Institute, University of Berne, Berne, Switzerland.

Cacon, S., Kontny, B., Bosy, J., Cello, G., Piccardi, L., Tondi, E., Drakatos, G., and Ganas, A., 2005. Local geodynamic researches in Polish Sudetes and the Mediterranean region, Reports on Geodesy, No. 2 (73), 231-244. 
Clarke, P.J., Davies, R.R., England, P.C., Parsons, B., Billiris, H., Paradissis, D., Veis, G., Cross, P.A., Denys, P.H., Ashkenazi, V., Bingley, R., Kahle, H.-G., Muller, M.-V., and Briole, P., 1998. Crustal strain in central Greece from repeated GPS measurements in the interval 1989-1997, Geophys. J. Int., 135(1), 195-214.

Dobrev, N., and Kostak, B., 2000. Monitoring tectonic movements in the Simitli graben, SW Bulgaria, Engineering Geology, 57(3-4), 179-192.

Drakatos, G., Petro, L., Ganas, A., Melis, N., Kostak, B., Kontny, B., Cacon, S., and Stercz, M., 2005. Monitoring of strain accumulation along active faults in the eastern Gulf of Corinth: Instrumentation and network setup, Acta Geodyn. Geomater., 2, No 1(137), 13-23.

Ganas, A., Pavlides, S. B., Sboras, S., Valkaniotis, S., Papaioannou, S., Alexandris, G. A., Plessa, A., and Papadopoulos, G. A., 2004. Active Fault Geometry and Kinematics in Parnitha Mountain, Attica, Greece, Journal of Structural Geology, 26, 2103-2118.

Goldsworthy, M., Jackson, J., and Haines, A.J., 2002. The continuity of active fault systems in Greece, Geophysical Journal International, 148, 596-618.

Hubert, A., King, G., Armijo, R., Meyer, B., and Papanastasiou, D., 1996. Fault Re-activation, Stress Interaction and Rupture Propagation of the 1981 Corinth Earthquake Sequence, Earth \& Planet. Sci. Lett., 142, 573-585.

Hugentobler, U, Sacher, S., and Fridez, P., 2001. Bernese GPS Software Version 4.2, Astronomical Institute, University of Berne, Switzerland.

Jackson, J.A., et al., 1982. Seismicity, normal faulting and the geomorphological development of the Gulf of Corinth (Greece): the Corinth earthquakes of February and March 1981, Earth \& Planet. Sc. Let., 57, 377-397.

King, G.C.P., Ouyang, Z.X., Papadimitriou, P., Deschamps, A., Gagnepain, J., Houseman, G., Jackson, J.A., Soufleris, C., and Virieux, J., 1985. The evolution of the Gulf of Corinth (Greece): an aftershock study of the 1981 earthquakes, Geophys. J. R. astr. Soc., 80, 677693.

Kokkalas, S., Pavlides, S., Koukouvelas, I., Ganas, A., and Stamatopoulos, L., in press. Paleoseismicity of the Kaparelli fault (eastern Corinth gulf): evidence for earthquake recurrence and fault behaviour, Bolletino di Geofisica Teoretica ed Applicata.

Kostak, B., and Cruden, D.M., 1990. The Moiré crack gauges on the crown of the Frank Slide, Can. Geotech. J., 27, 835-840.

Kostak, B., 1991. Combined indicator using Moiré technique, Proccedings of $3^{\text {rd }}$ International Symposium on Field Measurements in Geomechanics, Oslo, Norway, 53-60.

Maniatis, G., Lempp, CH., and Heinisch, H., 2003. 3D strain monitoring of onshore active faults at the eastern end of the Gulf of Corinth (Greece), J. Geodynamics, 36, 95-102.

Pavlides, S., Koukouvelas, I., Ganas, A., Kokkalas, S., Tsodoulos, I., Stamatopoulos, L., Goyntromichou, C., and Valkaniotis, S., 2003. Preliminary palaeoseismological results from the Kaparelli fault (Central Greece), Geophysical Research Abstracts, vol. 5, 07069, European Geophysical Society.

Roberts, G.P., and Ganas, A., 2000. Fault-slip directions in central and southern Greece measured from striated and corrugated fault planes: Comparison with focal mechanism and geodetic data, Journal of Geophysical Research, 105 (B10), 23443-23462pp.

Stemberk, J., Kostak, B., and Vilimek, V., 2003. 3D monitoring of active tectonic structures, Journal of Geodynamics, 36, 103-112. 